\title{
Geographical Information System Based Approach to Monitor Epidemiological Disaster: 2011 Dengue Fever Outbreak in Punjab, Pakistan
}

\author{
Shahbaz Ahmad \\ Department of Computer Science \\ NTU \\ Faisalabad, Pakistan
}

Muhammad Asif

Department of Computer Science NTU

Faisalabad, Pakistan

\author{
Muhammad Yasir \\ Department of Computer Science \\ UET \\ Faisalabad Campus, Pakistan \\ Shahzad Nazir \\ Department of Computer Science \\ NTU \\ Faisalabad, Pakistan
}

\author{
Muhammad Majid \\ IT Department, GPGC Samnabad \\ Faisalabad, Pakistan
}
Muhammad Umar Chaudhry
Deptt of elec \& comp eng,
Sungkyunkwan University
Suwon, republic of Korea

\begin{abstract}
Epidemiological disaster management, using geoinformatics (GIS), is an innovative field of rapid information gathering. Dengue fever, a vector-borne disease, also known as break bone fever, is a lethal re-emerging arboviral disease. Its endemic flow is causing serious effects to the economy and health at the global level. Even now, many under-developed and developing countries like Pakistan lack the necessary GIS technologies to monitor such health issues. The aim of this study is to enhance the effectiveness of developing countries through disaster management capabilities by using state-of-the-art technologies, which provide the measures to relief the disaster burden on public sector agencies. In this paper, temporal changes and regional burden for distribution of this disease are mapped using GIS tools. For the prevention of disaster burden, these types of studies are widely used to provide an effective help and relief. This study concludes that a public sector institute can use such tools for surveillance purpose and to identify the risk areas for possible precautionary measures.
\end{abstract}

\section{Keywords-GIS; Dengue; Hemorrhagic fever; Aedes aegypti}

\section{INTRODUCTION}

Dengue virus first appeared at the start of World War II [1]. Dengue fever is also known as break bone fever. It is a lethal re-emerging arboviral disease whose endemic flow [2] is having serious effects on the economy and health at the global level. It is a mosquito-borne fellow of Flaviviridae clan, which is the contributory fever [3]. Dengue is found in tropical and a sub-tropical area around the globe, mainly in urban and semi-urban region. The vital force behind the growth and development of dengue virus is temperature and climate. Climate and temperature are two known natural resources, which are not under human control.

Therefore, precautionary measures should be taken against dengue, and the breeding of mosquitoes should be avoided. It is observed that time period of growth from egg to adult is inversely related to temperature. It ranges from $7.2 \pm 0.2$ days at $35^{\circ} \mathrm{C}$ to $39.7 \pm 2.3$ days at $15^{\circ} \mathrm{C}^{[4]}$. Dengue virus is now almost blown out over the globe. In recent years, due to fast communication and transportation, it is estimated that there are 50 to 100 million cases of dengue fever and about 500,000 cases of dengue haemorrhagic fever per year, which requires hospitalization ${ }^{[5]}$.Dengue fever is normally caused by the bite of an infected Aedes aegypti mosquito, while symptoms of the disease automatically appear in about 5 to 7 days.

Dengue hemorrhagic fever was described in Southeast Asia, Manila in $1953^{[6]}$ and even in the start of 1950 about 9 countries were its victim. Dengue fever became more public in 1980 while at the end of 1990 s, it became the most substantial mosquito-borne disease ${ }^{[7]}$. After malaria, dengue is the disease that is distressing humans in a time span of 40 years. In 2009, an epidemic broke out in Bolivia, where 31000 cases were registered ${ }^{[8]}$.

The basic objective behind this research work is to portrait the affected area using GIS-based techniques into satellite images. The level of intensity and geographical identification of registered cases may help the government agencies to take preemptive measures before and also for future planning to recover from disaster situation.

\section{MATERIALS AND METHODS}

In order to find out the intensity of dengue in Punjab, we collected the registered cases from government and private hospitals inside Punjab. Figure 1 shows map of Pakistan highlighting the Punjab province. To carry out this research work, we practically adopted a qualitative research method as elaborated by John Creswell ${ }^{[9]}$. For the collection of data, a survey was designed specifically for the dengue patients. It includes all the symptoms related to this particular disease inside the patient. It also includes the demographical information of patients and their belongings. On the basis of collected data, we used the GIS-based application to embed the number of registered cases district wise. 


\section{STUDY AREA}

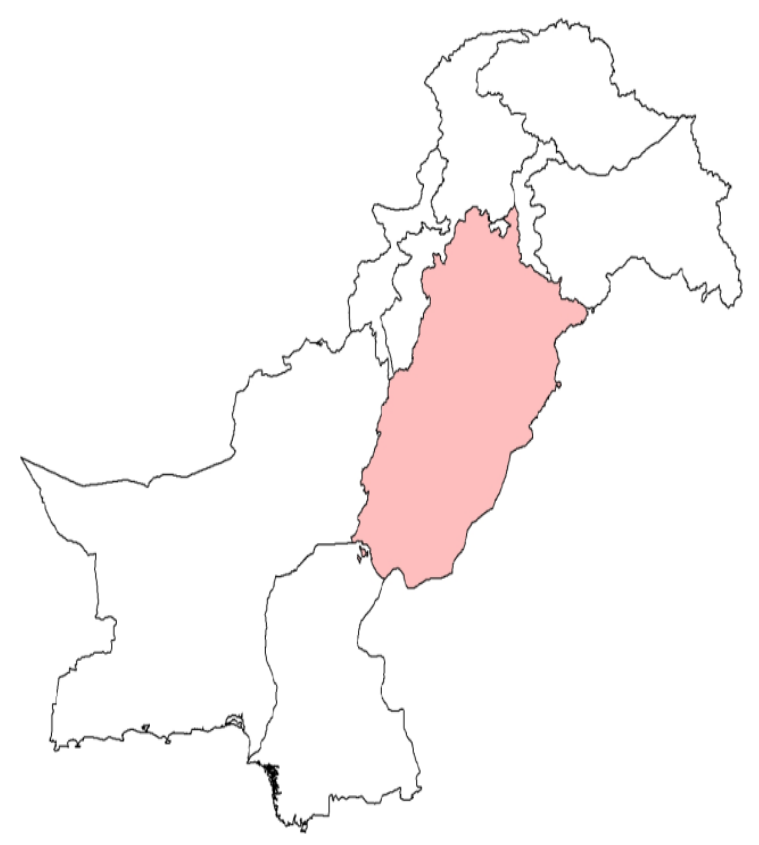

Fig. 1. Pakistan map reflecting punjab area

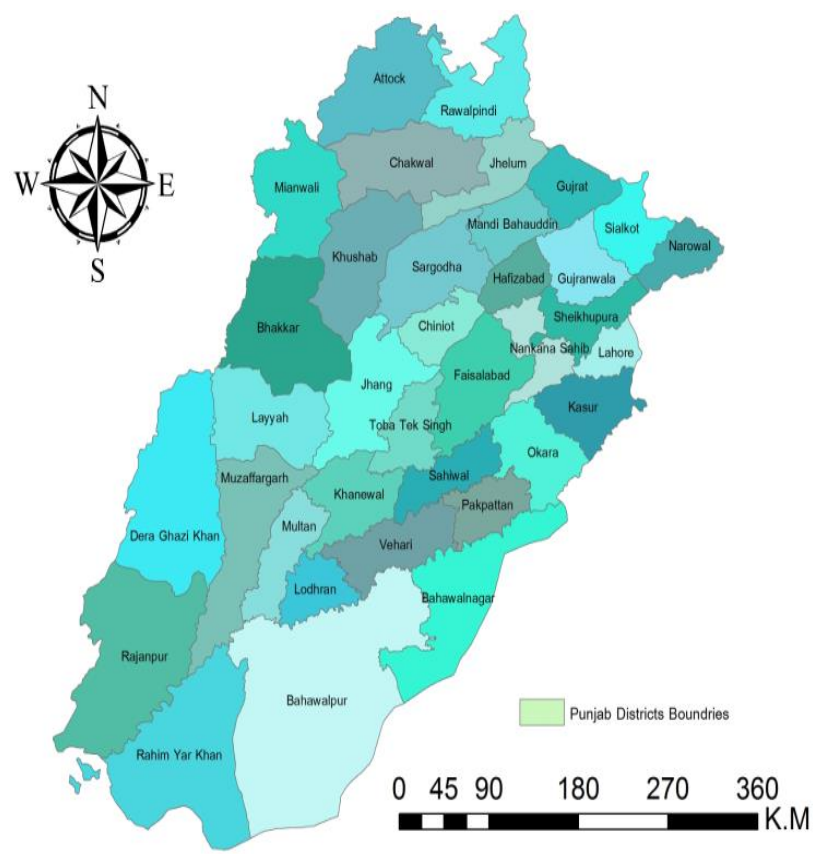

Fig. 2. Punjab Map reflecting Districts

Pakistan comprises four provinces while Punjab is major province of the Pakistan with respect to population, industry, and rich agricultural resource. Punjab is the most established, populated, and flourishing province of Pakistan. Figure 2 shows the map of the Punjab at district level. As it is hub of cultural, historical economic and administrative activities. Almost $62 \%$ population of the Pakistan residing in the province of Punjab ${ }^{[10]}$. We can say that in the development and progress of Pakistan this region of Punjab play vital role while if any dead lock occur in this region then whole country is affected as it having massive impact upon country. In the last few years, the dengue virus has spread throughout the country particularly in Punjab. It became an epidemic in a couple of years, especially in 2011.

Pakistan is a developing country with lack of resources and poor management. The number of patients is increasing yearly due to lack of awareness ${ }^{[11]}$.In year 2011 , about 300 people died while over 14000 were infected by dengue. Majority of the population affected due to dengue was from Lahore which is also the provincial metropolis of Punjab. In Pakistan, normally patient data in hospitals is not in electronic form. It is noted in registers in manual fashion so it was very hard to move from district to district and hospital to hospital to collect data of dengue patients.

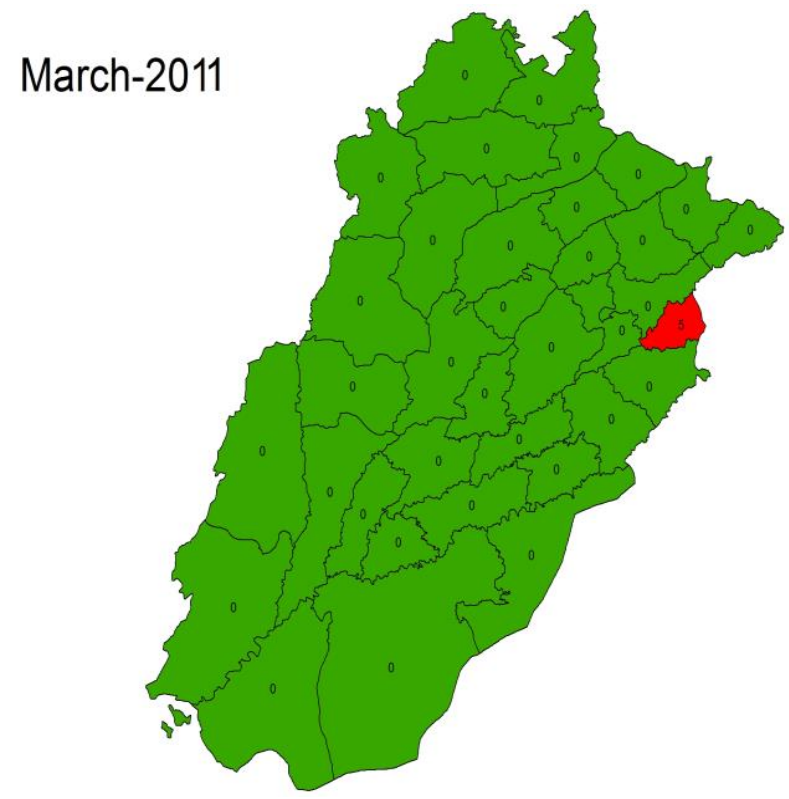

Fig. 3. Indicating origin of dengue in Punjab

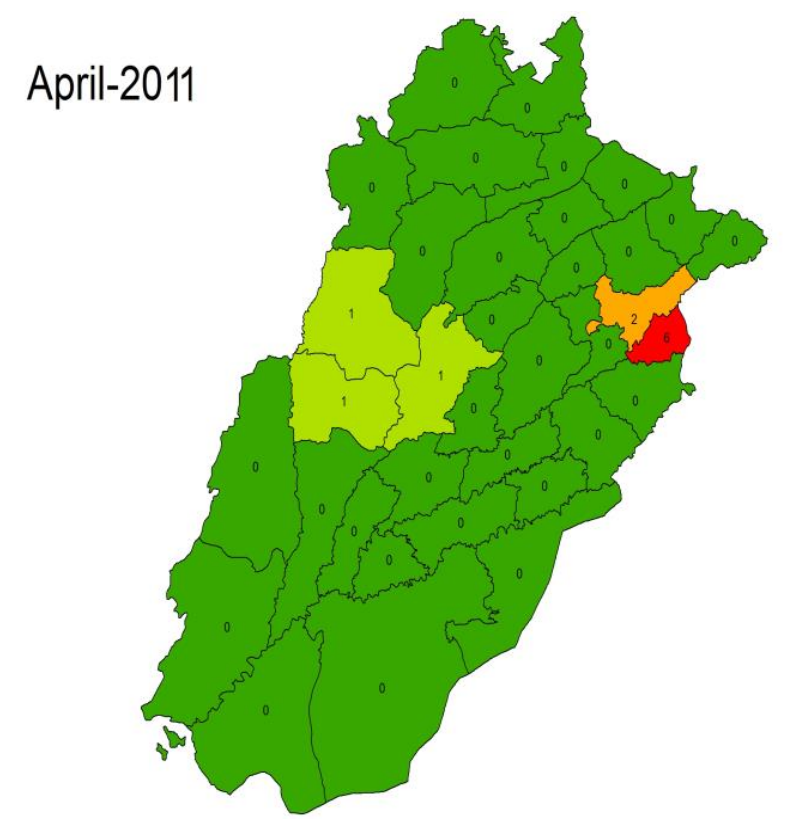

Fig. 4. Indicating flow and intensity of dengue in April 


\section{RESULTS}

In March 2011, dengue started in Lahore accidently and about five patients were admitted to different hospitals. Figure 3 indicates origin of dengue in Punjab in March. So it was dengue debut in Lahore in the province of Punjab as Lahore is located on the border of India and most populated city of the province in Pakistan. March is the end of winter and this period is not suitable for the growth of dengue virus as this virus was transferred by some foreign country through people and products [12]. Thus, Lahore proved to be a launching pad for dengue and in the very next month of April, the virus moved to the nearby city Sheikhupura which is just $37 \mathrm{~km}$ away from Lahore as it was natural for the virus to reach the nearest area as local bodies from Sheikhupura daily travel to Lahore and it is the commercial hub for the Punjab area. Figure 4 indicates the flow and intensity of dengue in April.

Meanwhile in the same month, viral attack moved directly to the Jhang, Leyya, and Bhakkar. This was due to daily transport of passengers. However, it was very minute in these four districts because only a single case was observed per district. So it was actually a start of the endemic flow of dengue. Actually this climate was not suitable for the growth of dengue virus. Treatment was also provided soon and dengue moved away from these four districts. However, it was still present in Lahore though on a small scale.

In the month of April, the weather starts getting slightly hot without any rain and it is the season of ripening of wheat and not favorable for dengue. In May, dengue moved to the district of Sargodha, Sahiwal, and Saialkot and this was due to transportation of passengers from Lahore to these areas. Figure 5 shows flow and intensity of dengue in May. The common point here is that Lahore is the dengue hub in Pakistan. In May, dengue cases decrease due to hot weather.

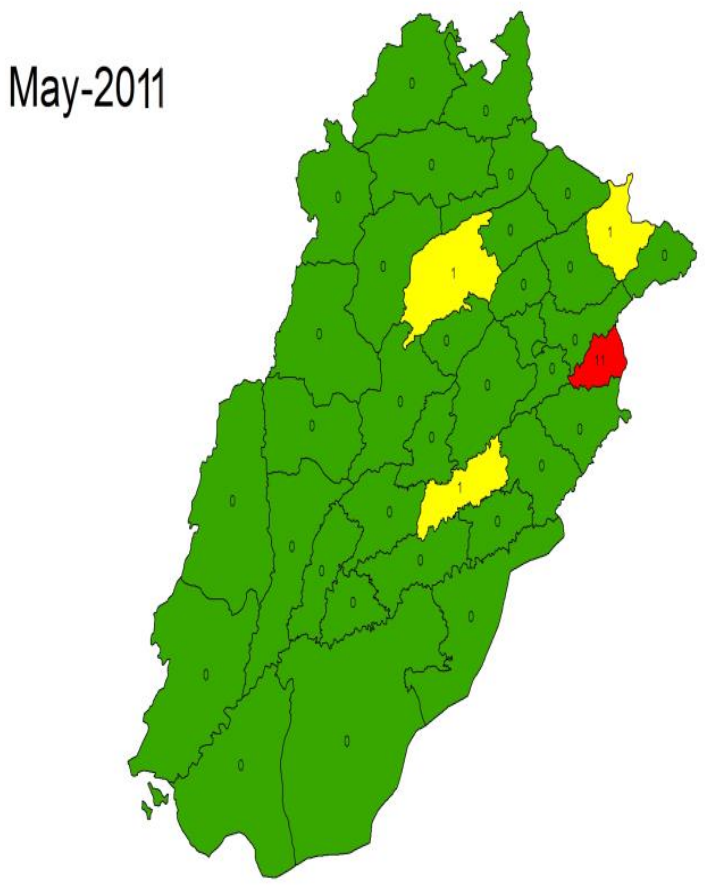

Fig. 5. Indicating flow and intensity of dengue in May

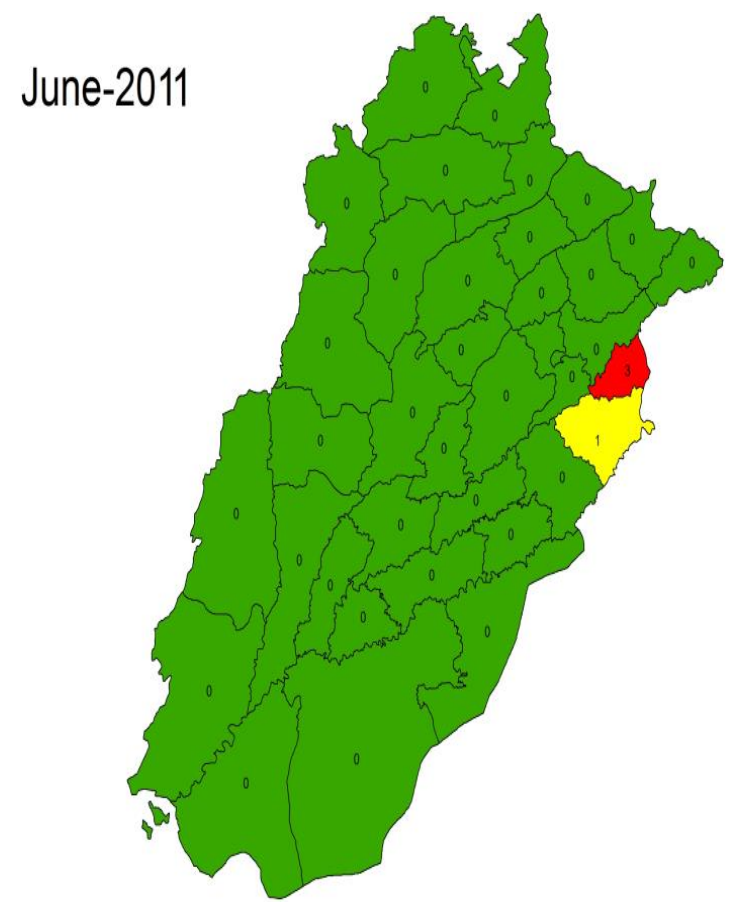

Fig. 6. Indicating flow and intensity of dengue in june

From March to May, the dengue virus moves through different districts of Punjab. However, its roots are strong in Lahore. In June, due to the weather, mosquitoes are completely wiped out. In June, the Kasur district was infected with just a single patient as this area is just $25 \mathrm{~km}$ away from Lahore. Figure 6 shows flow and intensity of dengue in June. July is also a hot month but with humidity and the growth of dengue still remained limited to Lahore with eight patients and a single patient was found in Attock. Figure 7 shows flow and intensity of dengue in July. Thus, in July, dengue created no problem for the government and public while the next month saw the spread of dengue in all of Punjab.

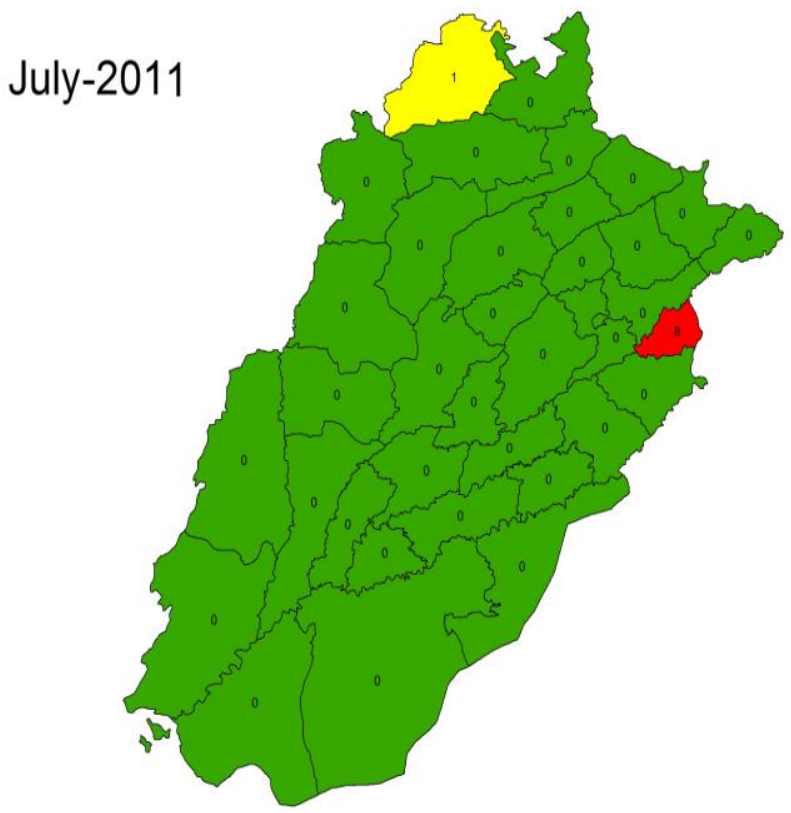

Fig. 7. Indicating flow and intensity of dengue in july 
Pakistan is located at a place where rains gear up at the end of July or beginning of August and humidity is also more. This climate is favorable for the growth of dengue virus and it widely spreads out in the month of August covering 27 of the 36 districts ( $75 \%$ of the area). The affected area can be seen in the map below and Lahore, Faisalabad, Multan, and Sheikhupura were most badly affected. Figure 8 shows the flow and intensity of dengue in August.

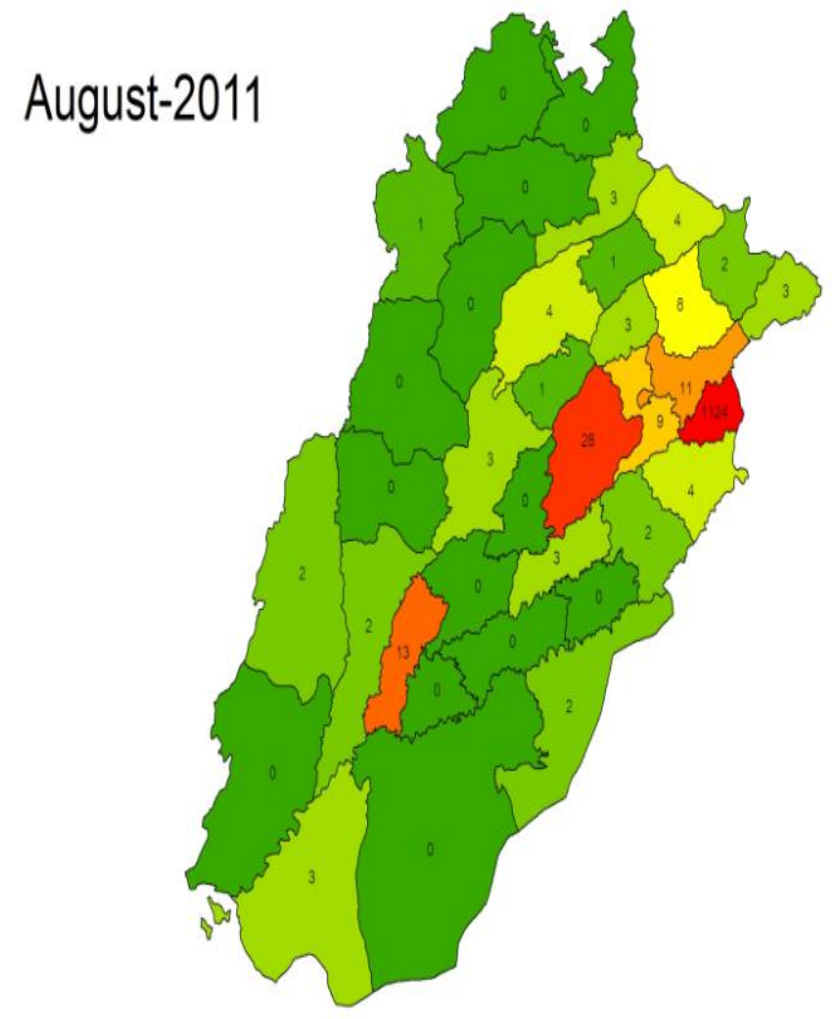

Fig. 8. Indicating high flow and intensity of dengue in August

In the month of August, almost whole of Punjab was affected and this caused loss of lives and fear among people. The government started giving out advertisements on prevention of dengue in an organized way for people to take precautionary measures. Some schools and colleges also announced holidays to control the intensity of the disease. In August, dengue covered almost $75 \%$ of the area of Punjab but its concentration was limited to four districts.

In the month of September, it covered $100 \%$ area of Punjab province and no district was without the viral infection. Its intensity also increased and spread over 14 districts as almost $39 \%$ area of Punjab was so badly infected. Figure 9 shows the flow and intensity of dengue in September. While $17 \%$ of the area was facing average intensity, about $44 \%$ area had a below average level. In September, about 11,000 patients were registered in different hospitals of Punjab. In the month of October, dengue devastation boomed much when compared to the month of September. Government agencies started spraying pesticides on the possible growth areas to control the spread of dengue.

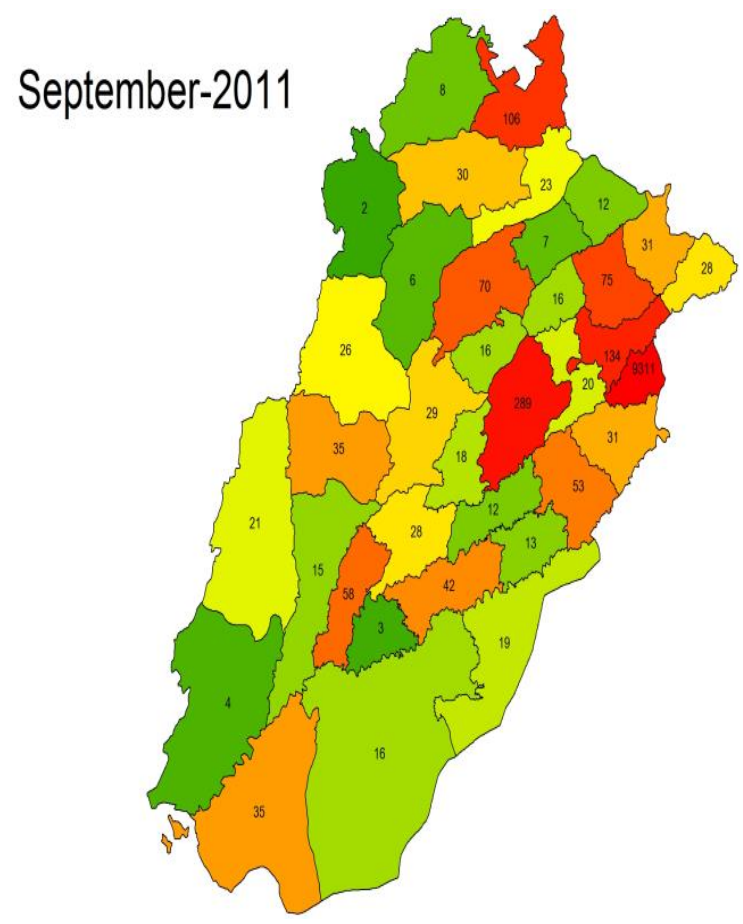

Fig. 9. Indicating high flow and intensity of dengue in September

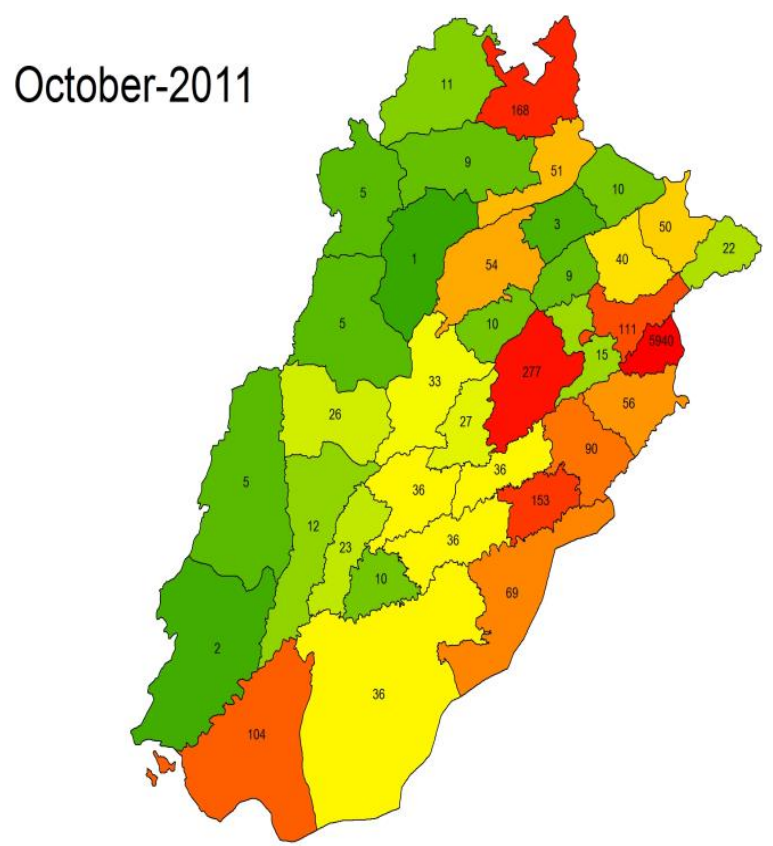

Fig. 10. Indicating high flow and intensity of dengue in October

In Lahore, Faisalabad, Sahiwal, Rawalpindi, and Rahim Yar khan, the intensity level of dengue remains the same in September and October. Figure 10 shows flow and intensity of dengue in October. While in November, the intensity lowers to about $19 \%$ compared to previous months. This also helped the government to fumigate the doubtful areas, and educate public through media and other modes of awareness. Figure 
11 shows the intensity and flow of dengue in November. Dengue-hub Lahore, Faisalabad along with Rawalpindi had the same intensity of dengue viral cases while the area of Bahawalpur, Rajanpur, and Layya were completely off dengue. Kasur, Okara, Pakpatan, and Sahiwal have more than the average incidents of dengue cases. Figure 12 indicates scaling criteria with respect to distance.

In December, surprisingly, the intensity was way lower $(20 \%)$ with respect to the number of cases arriving from different districts. Figure 13 shows the intensity and flow of dengue in December. Thus, $80 \%$ of the public got relief from dengue in December as in this month, the temperature falls by about $0-8$ centigrade. and dengue death occur due to high chill climate and in this way in December the dengue story come to and which left permanent mark upon the families of Punjab who lost their own, restless sleep, government spent millions of rupees for advertisement and equipment, heavy economic loss, public face heavy strain, education sector was also effected, many doctor teams from Sri Lanka, Thailand, and other countries also came for rescue of public from dengue.

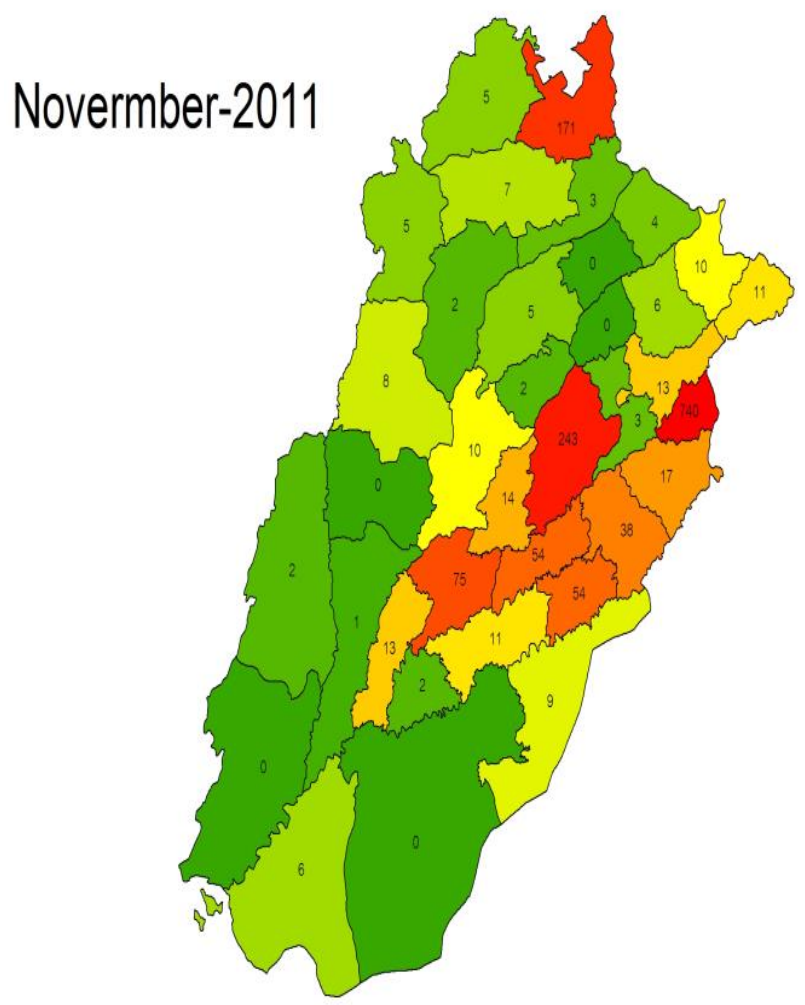

Fig. 11. Indicating high flow and intensity of dengue in November

When we observe the final map, we come to know that about 21,000 patients were influenced through this viral disease. Figure 14 shows the overall intensity and flow of dengue in the year 2011. Lahore proved to be a hub for dengue flow and top district with about 17,234 patients while Rajanpur was the least-affected district with just 6 patients.

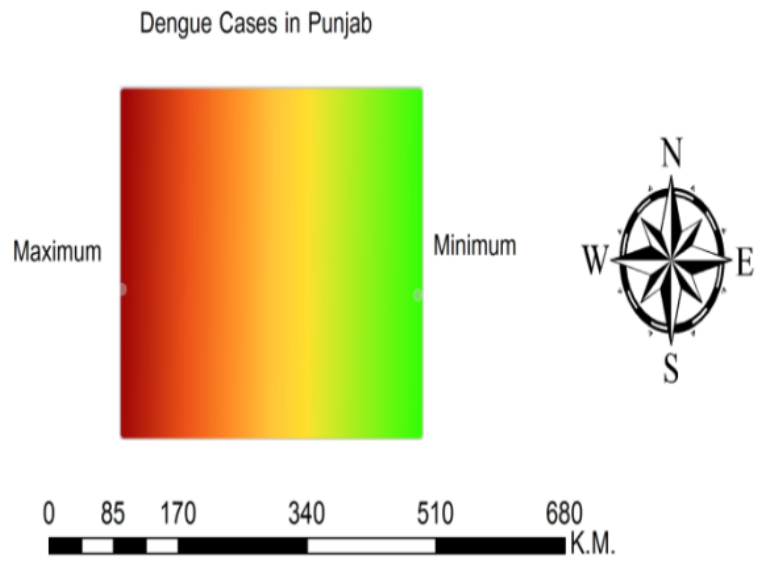

Fig. 12. Indicating scaling criteria with respect to distance

The dengue rampage was observed at Lahore, Faisalabad, Okara, Pakpatan, Khanewal, Rahim Yar Khan, Sheikhupura, Rawalpindi, and Sargodha, as these districts are adjacent to each other except, Rahim Yar Khan and Rawalpindi. Figure 15 indicates scaling criteria with respect to distance for final results.

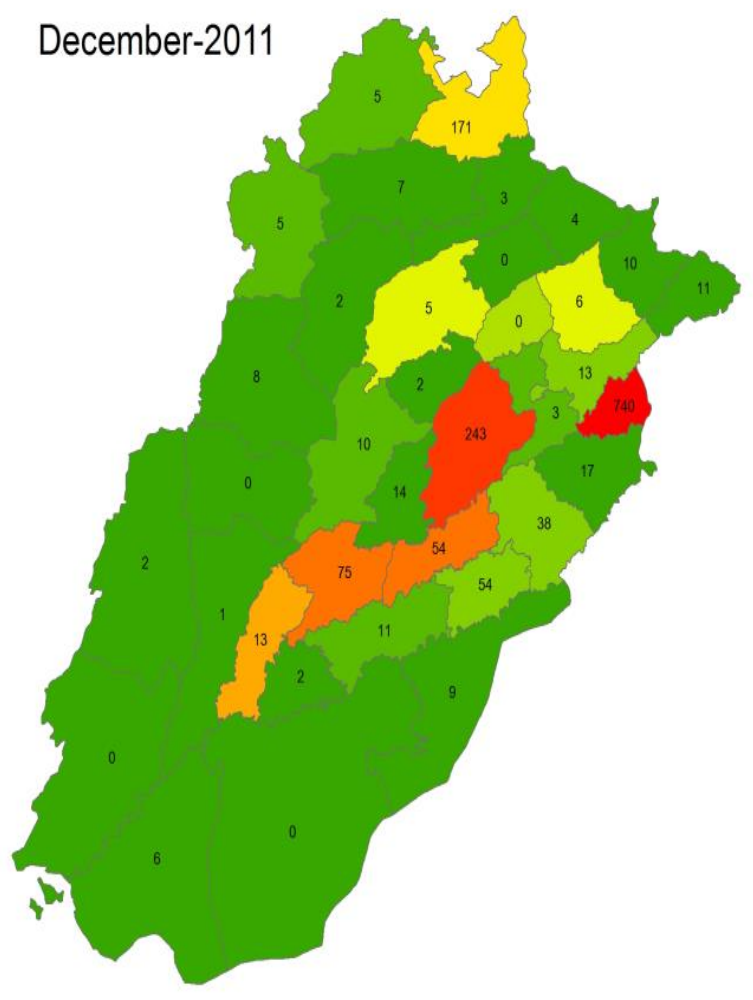

Fig. 13. Indicating high flow and intensity of dengue in December 


\section{Total Dengue Cases During 2011 in Punjab}

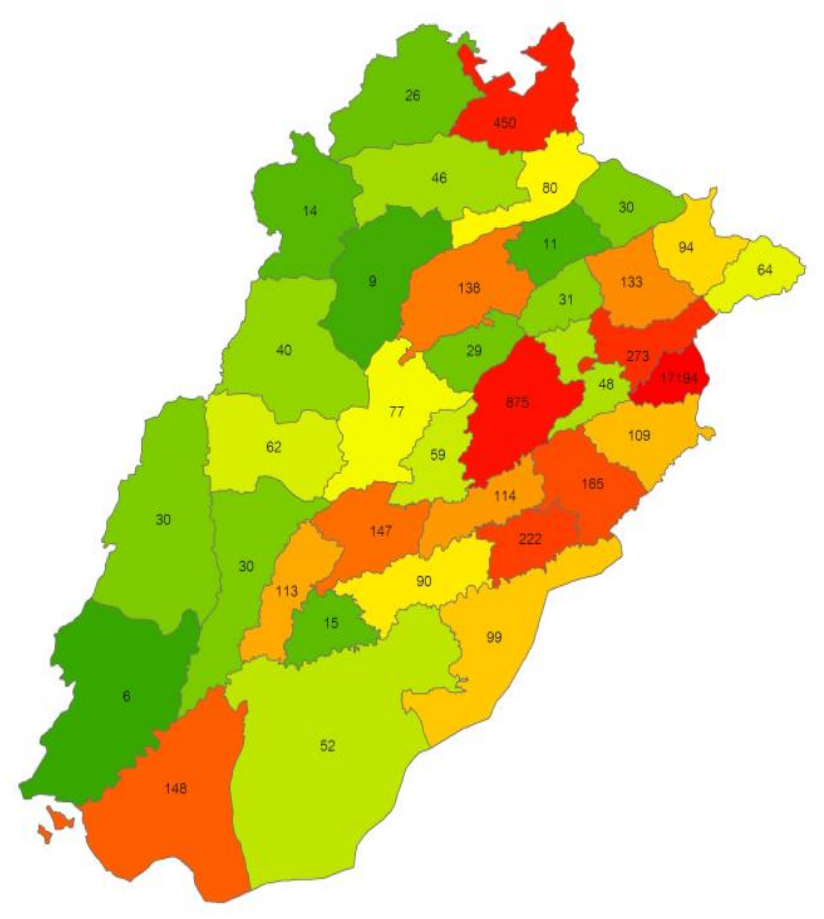

Fig. 14. Indicating over all flow and intensity of dengue in 2011
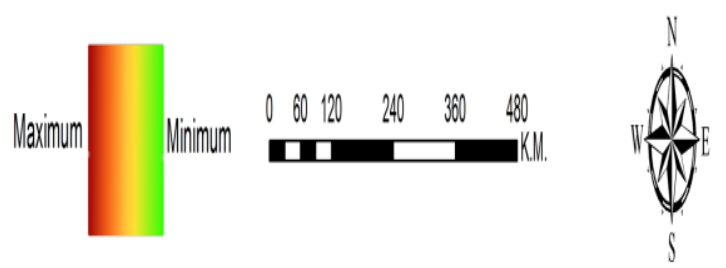

Fig. 15. Indicating scaling criteria with respect to distance for final results

\section{DISCUSSION}

We know that dengue disaster geared up from Lahore accidently in the month of March 2011 while the weather of Lahore around that time was the end of winter season. This means that it was not a suitable climate for mosquitoes. The question that arises is from where did dengue arrive in Lahore. Investigations indicated that it arrived from Bangkok, Thailand while its real source was 1000 second hand tractor tyres. These tyers contain some water inside them where dengue eggs were present and this resulted in the spread of the disease. We know that Lahore is the capital city of Pakistan and the commerical hub so due to transportation this virus moved to Layya, Jhang, and Bhakkar However, soon the virus vanished from these districts and emerged in others. The incidence was however not regular due to unfavorable weather round the year.

The real outbreak occurred in August when the rainy season starts since the temperature and weather are in favor. It covered the $75 \%$ area of Punjab and in later months it cover $100 \%$ area and now the expension of dengue was due to public movement because a dengue can cover maximum 300 meters area.so real source from district to district is fast transportation which cause to deploy viral infection from one place to other place.In tropical parts, dengue diffusion occurs throughout the year,while the temperature and humidity favour the existence of adult mosquitoes beyond their extrinsic incubation period. We know that winter and summer are not suitable for spread of dengue. It spreads mostly during the rainy months. The sprays destroy the eggs and future growth can be avoided. One female mosquito produces about 300 eggs in the life span of 14 days. Thus, the real task is to wipe away and destroy its eggs so that further growth can be avoided and life, economy, and health can be saved. Figure 16 indicates overall eruption district wise. Table 1 shows number of patients district wise.

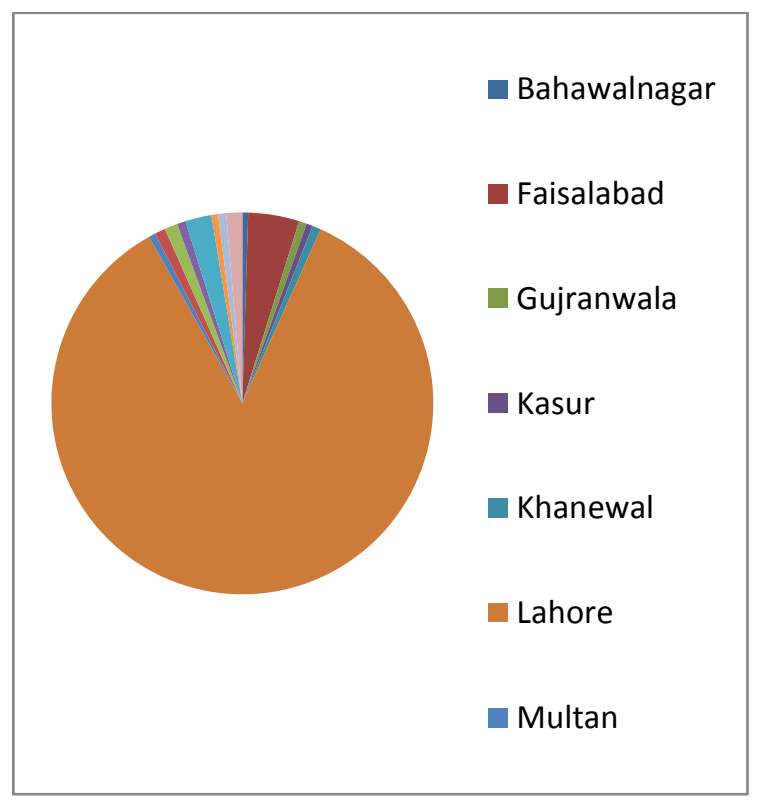

Fig. 16. Indicating over all eruption district wise

TAB LE I. Reflecting Patients District Wise

\begin{tabular}{|l|l|l|l|}
\hline Id & Dist code & District & Patient \\
\hline 1 & 601 & Attock & 28 \\
\hline 2 & 602 & Bahawalnagar & 99 \\
\hline 3 & 603 & Bahawalpur & 52 \\
\hline 4 & 604 & Bhakkar & 40 \\
\hline 5 & 605 & Chakwal & 46 \\
\hline 6 & 606 & Chiniot & 29 \\
\hline 7 & 607 & D.G Khan & 30 \\
\hline 8 & 608 & Faisalabad & 875 \\
\hline 9 & 609 & Gujranwala & 133 \\
\hline 10 & 610 & Gujrat & 29 \\
\hline 11 & 611 & Hafizabad & 31 \\
\hline 12 & 612 & Jhang & 77 \\
\hline 13 & 613 & Jhelum & 80 \\
\hline 14 & 614 & Kasur & 109 \\
\hline 15 & 615 & Khanewal & 147 \\
\hline 16 & 616 & Khushab & 9 \\
\hline 17 & 617 & Lahore & 17235 \\
\hline 18 & 618 & Layyah & 62 \\
\hline 19 & 619 & Lodhran & 15 \\
\hline 20 & 620 & M.Bahauddin & 11 \\
\hline 21 & 621 & Mianwali & 14 \\
\hline
\end{tabular}




\begin{tabular}{|l|l|l|l|}
\hline 22 & 622 & Multan & 113 \\
\hline 23 & 623 & Muzaffargarh & 30 \\
\hline 24 & 624 & Nankana & 48 \\
\hline 25 & 625 & Narowal & 64 \\
\hline 26 & 626 & Okara & 185 \\
\hline 27 & 627 & Pakpattan & 222 \\
\hline 28 & 628 & Rahim Yar & 148 \\
\hline 29 & 629 & Rajanpur & 6 \\
\hline 30 & 630 & Rawalpindi & 450 \\
\hline 31 & 631 & Sahiwal & 114 \\
\hline 32 & 632 & Sargodha & 138 \\
\hline 33 & 633 & Sheikhupura & 274 \\
\hline 34 & 634 & Sialkot & 94 \\
\hline 35 & 635 & T.T Singh & 59 \\
\hline 36 & 636 & Vehari & 90 \\
\hline
\end{tabular}

\section{CONCLUSION}

GIS approach is very effective and suitable for observing and indicating the damage caused by viral diseases. It is not possible to monitor the whole area without using GIS approach. No other technique except GIS can be helpful to this extent. Data that we process throught GIS can generate information in different respects. In this research, we accumulate dengue patients data from different districts and embed it on sattellite images. Thus, we can observe and indicate the nature of the disaster and its intensity in different regions so that precautionary measures can be taken in the areas where the intensity of dengue is higher.

In future, if we develop an integrated network of all the governmental systems and private hospitals where data should be processed in realtime then it can help the governmnet to observe the current situation of disaster time to time and positive decision can be taken to see the real time map and necessary action can be take to observe this real-time GIS approach. Thus, we can save lives, indicate and observe disaster, and manage the resources according to the situation. Thus, in future, this dynamic environment real-time GIS approach should be implemented in the integrated network of all hospitals.

\section{REFERENCES}

[1] Kurane I, Ennis FA. Cytokines in dengue virus infections: role of cytokines in the pathogenesis of dengue hemorrhagic fever. Sem Virol 1991;5:443-448.

[2] P. E. R. Dale, J. M. Knight, 2008.Wetlands and mosquitoes: a review, Wetlands Ecol Manage 16:255-276

[3] S.I.Hay, J.A.Omumbo, M.H.Craig (2000).Earth observation, geographic information system and plasmodium falciparum malaria in sub-Saharan Africa. Volume 47, 2000, Pages 173-174.

[4] W. Tun-Lin,T. R. Burkot,B. H. Kay effect of temperature and larval diet on development rates and survival of the dengue vector Aedes aegypti in north Queenland, Australia. Volume 14 issue 1, pages 31-37, march2000.

[5] Nisar Ahmad, Hina Afzal. Dengue fever treatment with Carica papaya leaves extracts. Asian Pacific Journal of Tropical Biomedicine (2011)330-333.

[6] Richard C Russell 1999.Mosquito-borne arboviruses in Australia:the current scene and implication of climate change for human health. Volume 28, Issue 6, 1 June 1998, Pages 955-969

[7] Duane J. Gubler, 2002.Epidemic dengue/dengue hemorrhagic fever as a public health, social and economic problem in the 21 st century. TRENDS in Microbiology Vol.10 No.2.

[8] Oyewale Tomori (1999).Impact of Yellow Fever on The Developing World, Advance in virus research. Volume 53, Pages 5-34.

[9] John Creswell, 2008.Research Design, Qualitative, Quantitative, and mixed methods approach.

[10] http://dengue.punjab.gov.pk/

[11] C.G. Hayes, S. Baqar(2004). West Nile virus in Pakistan. 1. Seroepidemiological studies in Punjab Province. Volume 76, Issue 4, 1982, Pages 431-436.

[12] Reich N. G. et al. Interactions between serotypes of dengue highlight epidemiological impact of cross-immunity. J R Soc Interface 10, 20130414 (2013). 